\title{
TRADISI BATUYANG MAULID MASYARAKAT SAMBA BAKUMPAI
}

\section{Title in English}

\section{Theresia Dessy Wardani I $^{\text {* }}$}

\section{Satriya Nugraha $2^{2}$}

* I FKIP Universitas PGRI Palangka Raya, Palangka Raya, Kalimantan Tengah, Indonesia.

2 Fakultas Hukum Universitas PGRI Palangka Raya, Palangka Raya, Kalimantan Tengah, Indonesia

*email: thedessywardani@gmail.com

\begin{abstract}
Abstrak
Perayaan Kelahiran Nabi Muhammad S.A.W. telah menjadi tradisi yang melekat bagi masyarakat di Indonesia, tidak terkecuali masyarakat Desa Samba Bakumpai Kecamatan Katingan Tengah Kabupaten Katingan Provinsi Kalimantan Tengah yang dikenal dengan Batuyang Maulid. Tujuan penulisan ini adalah mendeskripsikan kajian historis, makna serta relevasi perayaan Batuyang Maulid pada masyarakat Desa Samba Bakumpai. Metode yang digunakan adalah metode deskriptif yang terdiri dari prosedur, teknik pengumpulan serta analisis data yang memuat setiap unsur sumber data penelitian yang menghasilkan gambaran mengenai keberadaan tradisi Batuyang Maulid dalam masyarakat Desa Samba Bakumpai. Tradisi Batuyang Maulid adalah tradisi yang telah mengakar di adat islam masyarakat Desa Samba Bakumpai yang berasal dari perpaduan budaya islam dan hindu. Pelaksanaan perayaan Batuyang Maulid dilakukan dengan mengayun anak-anak dalam sebuah ayunan yang telah dihiasi dengan bermacam bunga, janur daun kelapa serta pinduduk. Setiap barang yang digunakan memiliki makna dan harapan untuk anak yang diayun, seperti Janur yang berbentuk ular lidi memiliki makna kebersihan, anak yang diayun diharapkan nantinya menyukai kebersihan, baik kebersihan diri mapun hatinya. Janur yang berbentuk bunga dan burung memiliki makna kebesaran, anak yang diayun diharapkan menjadi orang besar di kemudian hari nanti. Kemudian Bunga, buah, serta uang yang dijadikan hiasan juga memiliki makna, yaitu kejayaan. Tradisi Batuyang Maulid juga menggambarkan makna kehidupan masyarakat Desa Samba Bakumpai yang selalu mencerminkan sikap gotong royong, kekeluargaan, saling menghormati dan menjaga toleransi sesama warga Desa Samba Bakumpai.
\end{abstract}

Kata Kunci:

Batuyang Maulid

Samba Bakumpai

Tradisi

\section{Keywords:}

Batuyang Maulid

Samba Bakumpai

Tradition

\begin{abstract}
The Birth of the Prophet Muhammad S.A.W. has become an inherent tradition for people in Indonesia, including the people of Samba Bakumpai Village, Central Katingan District, Katingan Regency, Central Kalimantan Province, known as Batuyang Maulid. The purpose of this paper is to describe the historical study, the meaning and relevance of the celebration of Batuyang Maulid in the Samba Bakumpai Village community. The method used is a descriptive method that contains procedures, data collection and analysis techniques that contain each element of research data sources that produce a picture of the existence of the Batuyang Maulid tradition in the community of Samba Bakumpai Village. The Batuyang Maulid is a tradition that has taken root in the Islamic custom of the Samba Bakumpai Village community which originated from a blend of Islamic and Hindu culture. The celebration of Batuyang Maulid is carried out by swinging the children in a swing that has been decorated with various flowers, coconut leaves and pinduduk. Every item that is used has meaning and hope for the child being swung, such as a snakeshaped Janur that has a meaning of cleanliness, the child who is swayed is expected to later like cleanliness, both personal hygiene and heart. Flower and bird-shaped leaf have great significance, the child who is swinging is expected to become a big person later on. Then flowers, fruit, and money that are used as decoration also have meaning, namely glory. The Batuyang Maulid tradition also illustrates the meaning of community life in Samba Bakumpai Village, which always reflects mutual cooperation, kinship, mutual respect and maintaining tolerance among fellow residents of Samba Bakumpai Village.
\end{abstract}




\section{PENDAHULUAN}

Kebudayaan Indonesia walau beraneka ragam, namun pada dasarnya terbentuk dan dipengaruhi oleh kebudayaan besar lainnya seperti kebudayaan Eropa, Tionghoa, India, Arab dan lain sebagainya. Kebudayaan berasal dari kata buddayah yang berarti akal, maka tentunya budaya hanya dicapai dengan kemampuan akal yang tinggi tingkatanya yang dimiliki oleh manusia. (Ricklefs, 2016)

Kebudayaan merupakan sebagai seluruh sistem gagasan, tindakan dan hasil karya manusia dalam rangka kehidupan masyarakat yang dijadikan manusia dengan belajar. (Koentjaraningrat, 2000) Kebudayaan itu harus dipelajari, pembelajaran tersebut melalui enkulturasi yakni proses sosial budaya yang dipelajari dan ditransmisikan dari generasi ke generasi. Kebudayaan juga bukanlah sekumpulan hal yang berpisah-pisah satu sama lain. Sebaliknya, kebudayaan merupakan satu kesatuan dari banyak hal, termasuk sistem masyarakat. Penyampaian kebudayaan mencakup proses belajar dan mengajar, karena itulah pemahaman tentang hakikat kebudayaan sangat penting sekali artinya bagi orangorang yang bergerak dalam dunia pendidikan khususnya dan orang-orang yang terlibat dalam pembuat kebijakan pendidikan pada umumnya. Pendidikan, baik yang bersifat formal, informal, maupuan nonformal mendapat pengaruh dari kebudayaan yang ada dalam masyarakat.

Di sekolah, para siswa menerima warisan budaya yang telah dipersiapkan dan dirancang dalam kurikulum. Dalam lingkungan keluarga, anak-anak mendapatkan pengalaman budaya langsung dari orang tua, adik kakak, sanak saudara, pengasuh, dan orang-orang yang dekat dengannya. Dari kenyataan yang ada nampak bahwa kebudayaan perlu dikembangkan dengan cara pendidikan. Anak muda tidak akan matang secara budaya tanpa ditunjukkan bagaimana menjadi dewasa. Anak-anak juga menyadari bahwa teknik kedewasaan mesti dipelajari dari orang dewasa. Masyarakat paham bahwa penyampaian kebudayaan mereka tidak dibiarkan terjadi secara kebetulan saja. Di dalam kebudayaan terdapat adat atau kebiasaan. Kebiasaan dapat diartikan serupa dengan pengertian adat. Bedanya, kebiasaan dipergunakan untuk perseorangan, sedangkan adat digunakan oleh sekelompok orang. Pada masyarakat indonesia masih banyak pandangan dan anggapan tentang alam gaib dan kepercayaan lain yang belum seluruhnya lenyap. Oleh sebab itu, banyak sekali tradisi dan kepercayaan yang melekat benar pada masyarakat, sehingga dilestarikan secara turun temurun.

Pengertian kebiasaan dan tradisi dalam bahasa latin: traditio, "diteruskan" atau kebiasaan, dalam pengertian yang paling sederhana adalah sesuatu yang telah dilakukan untuk sejak lama dan menjadi bagian dari kehidupan suatu kelompok masyarakat, biasanya dari suatu negara, kebudayaan, waktu, atau agama yang sama. (Sunarwinadi, 1990) Hal yang paling mendasar dari tradisi adalah adanya informasi yang diteruskan dari generasi ke generasi baik tertulis maupun (sering kali) lisan, karena tanpa adanya ini, suatu tradisi dapat punah. Definisi kebiasaan: sesuatu yang kamu lakukan secara periodik (present tense/saat ini). Dulunya, (past tense) hal itu tidak pernah dilakukan, tapi sekarang jadi melakukannya secara periodik.

Pengertian adat istiadat. Adat Istiadat adalah aneka kelaziman dalam suatu negeri yang mengikuti pasang naik dan pasang surut situasi masyarakat. Kelaziman ini pada umumnya menyangkut pengejawatahan unjuk rasa seni budaya masyarakat, seperti acara-acara keramaian anak negeri, seperti pertunjukan randai, saluang, rabab, tari-tarian dan aneka kesenian yang dihubungkan dengan upacara perhelatan perkawinan, pengangkatan penghulu maupun untuk menghormati kedatangan tamu agung. Adat istiadat semacam ini sangat tergantung pada situasi sosial ekonomi masyarakat.

Tradisi (bahasa Latin: traditio, artinya diteruskan) menurut artian bahasa adalah sesuatu kebiasaan yang berkembang di masyarakat baik, yang menjadi adat kebiasaan, atau yang diasimilasikan dengan ritual adat 
atau agama. Atau dalam pengertian yang lain, sesuatu yang telah dilakukan untuk sejak lama dan menjadi bagian dari kehidupan suatu kelompok masyarakat, biasanya dari suatu negara, kebudayaan, waktu, atau agama yang sama. Biasanya tradisi ini berlaku secara turun temurun baik melalui informasi lisan berupa cerita, atau informasi tulisan berupa kitab-kitab kuno atau juga yang terdapat pada catatan prasasti-prasasti. (Asbihani, 2017)

Tradisi-tradisi ini biasanya dihubungkan antara suatu kegiatan manusia dengan aktivitas alam sekitar, antar manusia, manusia dengan sang penguasa (bentuk umum). Memang secara naluriah, manusia mengakui akan adanya sebuah penguasaan 'sesuatu' terhadap 'sesuatu' agar 'sesuatu' tersebut tidak mengganggu aktivitas manusia dalam kehidupan. (Kalau dalam Islam adalah Fitrah ketuhanan yang sudah ada terpatri sejak zaman azali, sebagaimana saat manusia masih di alam ruh yang diminta kesaksian akan keberadaan Sang Penciptanya.

Salah satu tradisi dalam agama islam yang ada di desa Samba Samba Bakumpai Kecamatan Katingan Tengah, Kabupaten Katingan Provinsi Kalimantan Tengah, yaitu tuyang maulid. Tradisi ini biasanya dilakukan pada bulan maulid untuk merayakan kelahiran nabi Muhammad S.A.W. Tradisi merayakan maulid bukan merupakan suatu hal yang asing khususnya di Negara Indonesia. Pada setiap daerah yang berbeda tradisi merayakan maulid bisa dilaksanakan dengan melakukan pengajianpengajian kecil. Pemerintah Indonesia juga menjadikan peringatan Maulid Nabi Muhammad S.A.W sebagai hari libur nasional sebagai upaya menghargai tradisi maulid kepada masyarakat Indonesia yang mayoritas beragama muslim. Salah satu contoh perayaan maulid nabi yaitu di dusun mlangi provinsi Yogyakarta, tradisi maulid nabi dirayakan dengan membaca sholawat yang diiringi dengan lagu/gending jawa yang sering disebut masyarakat desa mlangi sebagai gladen yang dipimpin oleh seorang dalang sholawat. (Nadia, 20II) Lain halnya perayaan maulid nabi pada masyarakat Sasak.
Masyarakat Sasak dalam merayakan maulid nabi memiliki bermacam tradisi yang unik, salah satu nya adalah menyiapka tiga jenis dulang atau sajian bagi para tamu undangan yang akan datang ke masjid untuk merayakan maulid nabi. Tiga jenis dulang ini adalah dulang nasik, dulang jaje dan dulang penamat. Dulang ini akan menjadi santapan para jamaah masjid dalam rangkaian perayaan maulid nabi yang seperti ceramah pengajian, tahlilan dan zikiran. (Mansyur, 2005)

Pada tradisi Batuyang Maulid Desa Samba Bakumpai yang dilakukan adalah mengayun anak-anak dalam sebuah ayunan yang telah dihiasi, dan dilantunkan shalawat-shalawat nabi. Dalam pelaksanaan tradisi ini terdapat makna dan relevansi dalam kehidupan sekarang. Makna dan relevansi inilah yang menjadi ide utama dalam penulisan naskah ini.

Tulisan ini bertujuan untuk mendeskripsikan kajian historis, makna serta relevansi tradisi Batuyang Maulid bagi masyarakat di Desa Samba Bakumpai Kecamatan Katingan Tengah.

\section{METODOLOGI}

Metode yang digunakan dalam tulisan ini adalah metode deskriptif, dengan tujuan menggambarkan setiap data penelitian yang didapatkan melalui prosedur dan teknik pengumpulan data antara lain observasi, pemilihan narasumber penelitian, rekaman informasi secara lisan (Sugiyono, 20/4) yang terkait dalam pembentukan rekonstruksi tradisi batuyang maulid. Selanjutnya dilakukan pengolahan data yang kemudian akan ditransformasikan melalui analisis data melalui langkah-langkah berikut:

I. Membaca teks yang sudah ditranskripkan.

2. Mengidentifikasi teks cerita berdasrkankan rumusan masalah yang telah ditetapkan.

3. Mengkodifikasi yaitu memberikan kode sesuai dengan kategori yang berkaitan dengan rumusan masalah.

4. Mengklasifikasi yaitu pengelompokan data sesuai dengan rumusan masalah. 
5. Menginterpretasi yaitu memberi makna atau melakukan analisis secara deskriptif bagian asal mula dan makna serta relevansi dalam tradisi Batuyang Maulid di Desa Samba Bakumpai Kecamatan Katingan Tengah dengan kehidupan sekarang.

6. Membuat simpulan ( (Endaswara, 20I I)

Sumber data yang telah dianalisis akan didokumentasikan dan ditranskripkan ke dalam bentuk teks sebagai bentuk penyimpulan hasil penelitian.

\section{HASIL DAN PEMBAHASAN}

\section{a. Asal Mula Tradisi Batuyang Maulid di Desa Samba Bakumpai Kecamatan Katingan Tengah}

Tradisi Batuyang Maulid yang ada di desa Samba Bakumpai ini, merupakan tradisi yang dibawa oleh suku Banjar yang merantau ke Provinsi Kalimantan Tengah. Suku Banjar memang terkenal sebagai suku yang suka merantau untuk berdagang. Dari sinilah mereka juga menyebarkan agama, kebudayaan, serta kebiasakebiasan dari tempat asalnya Kalimantan Selatan. Dalam pelaksanaan tradisi Batuyang Mualid yang ada di desa Samba Bakumpai ini nampak sekali perpaduan budaya Islam dan Hindu. Di mana diketahui agama yang pertama masuk di pulau Klaimantan adalah agama Hindu. Setelah masuknya agama islam dan menjadi agama mayoritas di Kalimantan Selatan, budaya peninggalan Hindu masih mengakar di adat islam lokal namun membaur dengan ajaran agama Islam. Hal inipun sama dengan yang ada di desa Samba Bakumpai.

Di desa Samba Bakumpai tidak semua anak akan mengikuti tradisi Batuyang Maulid ini, hanya anak-anak dari keturunan tertentu saja yang mengikutinya. Hal ini harus mereka laksanakan agar anak-anak mereka tidak sakit. Jika mereka tidak melaksankannya anak-anaknya dapat sakit yang tidak kunjung sembuh, dan dapat membawa kematian jika dibiarkan. Untuk itulah tradisi Batuyang Maulid ini masih dilaksanakan di desa Samba
Bakumpai Kecamatan Katingan Tengah, dengan tujuan menghindari segala macam penyakit.

\section{b. Makna Tradisi Batuyang Maulid Di Desa Samba Bakumpai Kecamatan Katingan Tengah}

Pada pelaksanaan tradisi Batuyang Maulid di desa Samba Bakumpai ini, anak-anak hingga orang dewasa turut serta dalam pelaksanaannya. Anak-anak diayun menggunakan ayunan khusus yang telah dihiasi dengan berbagai macam bunga, janur daun kelapa, uang, serta sesajen berupa beras, kelapa, benang hitam, jarum, dan gula merah atau putih yang dimasukan ke dalam suatu wadah atau dikenal juga dengan pinduduk. Kain yang digunakan untuk mengayun anak laki-laki dan perempuan juga berbeda. Kain untuk anak perempuan kuning dan anak untuk anak laki-laki berwarna kuning bercampur merah. Kain untuk dijadikan ayunan harus berjumlah ganjil, biasanya berjumlah tiga.

Setiap barang yang digunakan dalam pelaksanaan tradisi Batuyang Maulid ini memiliki makna tersendiri dan harapan-harapan untuk anak yang ayun itu. Janur yang berbentuk ular lidi memiliki makna kebersihan, anak yang diayun diharapkan nantinya menyukai kebersihan, baik kebersihan diri mapun hatinya. Janur yang berbentuk bunga dan burung memiliki makna kebesaran, anak yang diayun diharapkan menjadi orang besar di kemudian hari nanti.

Bunga, buah, serta uang yang dijadikan hiasan juga memiliki makna, yaitu kejayaan. Anak-anak ini kelaka diharapkan hidupnya dianugerahi dengan kejayaan di masa depannya. Kain kuning pada ayunan memiliki makna kebijaksanaan, diharapkan nantinya anak-anak itu akan menjadi orang yang bijaksana dalam bertingkah, berlaku, dan dalam pengambilan keputusan. 
c. Relevansi tradisi Batuyang Maulid di Desa Samba Bakumpai Kecamatan Katingan Tengah dengan kehidupan sekarang

Relevan berarti berkaitan, bersangkut paut, berguna secara langsung. Tradisi batuyang maulid yang ada di desa Samba Bakumpai ini masih relevan dalam kehidupan sekarang. Relevansi ini terlihat dari sikap gotong royong, kekeluargaan, saling menghormati antarwarga dalam pelaksanaan tradisi batuyang maulid ini.

Gotong royong merupakan istilah Indonesia untuk bekerja bersama-sama untuk mencapai suatu hasil yang didambakan. Gotong royong terlihat dari awal persiapan, pelaksanaan, hingga setelah selesainya tradisi batuyang maulid ini dilaksanakan. Warga sekitar saling bekerjasama untuk mempersiapkan keperluan untuk pelaksanaan tradisi batuyang maulid ini. Pada ssat pelaksanaan tidaklah mungkin hanya dapat dilakukan oleh satu orang saja, namun juga memerlukan orang lain dalam pelaksanaannya. Setelah selasai pelaksanaan tradisi ini, gotong royong masih nampak, yaitu memberskan alat dan bahan yang telah digunakan selama tradisi batuyang maulid ini berlangsung.

Sikap Kekeluargaan adalah sikap hubungan antar manusia yang membentuk rasa saling memiliki dan terhubung satu sama lain dan menghadapi masalah maupun kebahagiaan bersama. Di desa Samba Bakumpai, hampir semua tradisi yang dilaksanakan masih tergambar sikap-sikap kekeluargaan. Begitu pula dalam pelaksanaan tradisi batuyang maulid ini, kekeluargaan masih terasa kental saat baik dalam persiapan, pelaksanaan, maupun setelah selasainya kegiatan.

Sikap saling menghormati adalah sifat yang selalu hormat sesama dan tidak saling mengejek atau mencemooh sesama manusia. Tradisi batuyang maulid ini tidak semua dilaksanakan oleh warga yang ada di desa Samba Bakumpai. Namun, hal ini tidak menjadikan warga yang melaksanakan itu merasa tinggi hati, ataupun sebaliknya warga yang tidak melaksanakan merasa berkecil hati. Tentunya hal ini dapat berdampingan saja karena sudah tertanam sikap saling menghormati tadi. Sebagai contoh ada salah satu keluarga yang melaksanakan tradisi batuyang maulid ini, pada saat pelaksaan itu hampir satu hari diisi dengan menyanyikan pujian-pujian kepada nabi Muhammad S.A.W. tentunya hal ini terdengar berisik dan gaduh, namun bagi tetangga yang di sebelah hal ini bukanlah hal yang mengganggu, malah mereka juga ikut membantu dalam pelaksanaan kegiatan tradisi tersebut. Hal ini dapat terjadi tanpa ada yang mearsa dirugikan Karena sikap saling menghormati tadi telah tertanam dengan baik antar warga yang ada di desa Samba Bakumpai ini.

\section{KESIMPULAN}

Tradisi Batuyang Maulid yang ada di desa Samba Bakumpai ini, merupakan tradisi yang dibawa oleh suku Banjar yang merantau ke Provinsi Kalimantan Tengah. Budaya peninggalan hindu masih mengakar kuat di adat lokal, namun membaur dengan ajaran agama Islam. Hal inipun sama dengan yang ada di desa Samba Bakumpai. Pelaksanaan tradisi Batuyang Maulid dilakukan dengan mengayun anak-anak menggunakan ayunan khusus yang telah dihiasi dengan berbagai macam bunga, janur daun kelapa, uang, serta pinduduk. Setiap barang yang digunakan dalam pelaksanaan tradisi Batuyang Maulid ini memiliki makna tersendiri dan harapan-harapan untuk anak yang ayun itu. Janur yang berbentuk ular lidi memiliki makna kebersihan, anak yang diayun diharapkan nantinya menyukai kebersihan, baik kebersihan diri mapun hatinya. Janur yang berbentuk nunga dan burung memiliki makna kebesaran, anak yang diayun diharapkan menjadi orang besar di kemudian hari nanti. Bunga, buah, serta uang yang dijadikan hiasan juga memiliki makna, yaitu kejayaan. Anak-anak ini kelaka diharapkan hidupnya dianugerahi dengan kejayaan di masa depannya. Kain kuning pada ayunan memiliki makna kebijaksanaan, diharapkan nantinya anak-anak itu akan menjadi orang 
yang bijaksana dalam bertingkah, berlaku, dan dalam pengambilan keputusan.

Kehadiran dan kelestarian tradisi Batuyang Maulid merupakan perwujudan kehidupan masyarakat Desa Samba Bakumpai yang tercermin dari sikap gotong royong, kekeluargaan, serta saling menghormati dan toleransi antar warga dalam pelaksanaan tradisi Batuyang Maulid.

\section{UCAPAN TERIMA KASIH}

Para penulis juga mengucapkan terima kasih kepada LP2M Universitas PGRI Palangka Raya yang telah memberikan arahan serta bantuan dalam proses penyelesaian penelitian Batuyang Maulid ini, kemudian ucapan terima kasih juga kami berikan kepada para Damang, Mantir dan para tokoh adat serta masyarakat Desa Samba Bakumpai Kecamatan Katingan Tengah Kabupaten Katingan, serta yang terakhir ucapan terima kasih kami berikan kepada rekan-rekan mahasiswa (Herniati, Rupiadi, dan Deby Aryani Syafitri) dan dosen di Universitas PGRI Palangka Raya yang tidak bisa kami sebutkan satu persatu.

\section{REFERENSI}

Asbihani, A. (2017, Oktober). Eksistensi Tradisi Mandi Safar di Desa Tanjung Punak Kecamatan Rupat Utara Kabupaten Bengkalis. Jurnal Online Mahasiswa Fakultas IImu Sosial dan IImu Politik, 4(2), I- 14.

Endaswara, S. (20II). Metodologi Penelitian Sosiologi Sastra. Yogyakarta: CAPS.

Koentjaraningrat. (2000). Kebudayaan, Mentalitas, dan Pembangunan. Jakarta: PT. Gramedia Pustaka Utama.

Mansyur, Z. (2005). Tradisi Maulid Nabi Dalam Masyarakat Sasak. Ulumuna, 9(I), 90-103.

Nadia, Z. (20II). Tradisi Maulid pada Masyarakat Mlangi Yogyakarta. Esensia:Jurnal IImu-Ilmu Ushuluddin, I2(2), 367-384.

Ricklefs, M. C. (20|6). Sejarah Indonesia Modern. Yogyakarta: Gadjah Mada University Press.
Sugiyono. (2014). Memahami Penelitian Kualitatif. Bandung: CV. Alfabeta.

Sunarwinadi, I. (1990). Komunikasi antar Budaya. Depok: Fakultas IImu Sosial Universitas Indonesia. 